\title{
ORGANO-CHLORINE PESTICIDE RESIDUES IN OKRA AND BRINJAL COLLECTED FROM PERI-URBAN AREAS OF BIG CITIES OF PUNJAB- PAKISTAN
}

\author{
Muhammad Atif Randhawa1, Qamar Uz Zaman Abid', Faqir Muhammad Anjum¹, Abdul \\ Shakoor Chaudhary ${ }^{2}$, Muhammad Wasim Sajid ${ }^{3 *}$ and Anees Ahmed Khalil ${ }^{1}$ \\ ${ }^{1}$ National Institute of Food Science and Technology, University of Agriculture, Faisalabad, Pakistan; \\ ${ }^{2}$ School of Agriculture, Food and rural development, Newcastle University, United Kingdom; \\ ${ }^{3}$ Department of Biosciences, COMSATS Institute of Information Technology, Sahiwal \\ "Corresponding author's e-mail: sagitws@gmail.com
}

\begin{abstract}
Exposure of organo-chlorine pesticides as a result of utilization of okra and brinjal to urban population has been estimated in this study. GC-ECD was used for quantification of $\alpha$-endosulfan, $\beta$-endosulfan, endosulfan sulphate, $\mathrm{HCH}$, Gamma $\mathrm{HCH}$, DDT and DDE residues from 180 samples of okra and brinjal collected from peri-urban farming area of Faisalabad, Multan and Gujranwala. Quantification of pesticide residues revealed that 280 samples were contaminated and 23 samples showed residues value higher than MRL'S. Out of 280 contaminated samples, 50 samples were contaminated with $\alpha$-endosulfan, 48 samples with $\beta$-endosulfan, 49 with endosulfan sulphate, 27 samples with $\mathrm{HCH}, 33$ samples with gamma $\mathrm{HCH}, 34$ samples with DDT and 39 were contaminated with DDE. Overall, 7.33\% samples of okra and 6.44\% samples of brinjal contaminated with $\alpha$-endosulfan exceeded EU MRL of $0.05 \mathrm{mg} \mathrm{kg}^{-1}, 8.67 \%$ samples of okra and $7.33 \%$ samples of brinjal had $\beta$-endosulfan residue level above MRL of $0.05 \mathrm{mg} \mathrm{kg}^{-1}$ and approximately, $8.67 \%$ samples of okra and $7.33 \%$ samples of brinjal had endosulfan sulphate residue level above MRL of $0.05 \mathrm{mg} \mathrm{kg}^{-1}$. While, no sample of okra and brinjal had $\mathrm{HCH}, \mathrm{Gamma} \mathrm{HCH}$, DDT and DDE level above MRL of 0.01, 0.01, 0.05 and $0.05 \mathrm{mg} \mathrm{kg}^{-1}$, respectively. This study may be helpful in creating a database about regional exposure of urban population and facilitate in evaluation of potential threat and risk to their health in daily life.
\end{abstract}

Keywords: Vegetables, contamination, risk assessment, insecticides, toxicity.

\section{INTRODUCTION}

Vegetables are vital constituent of human diet as they are rich source of minerals and vitamins. Depending upon total recommended intake values, vegetables in general, provide 9\% of calories, $19 \%$ of iron and 16\% of magnesium (Iqbal et al., 2009). Despite of their nutritional benefits, raw fresh vegetables can also be a source of toxic and harmful pesticides. Pesticides are a term commonly used for chemical substances used in modern agriculture practices that are helpful in protecting crops against different diseases and pests (Guler et al., 2010). In agriculture sector, the use of pesticides by the farmers around the globe is directly related to amplification of farm yield. Depending on the targeted pests, pesticides can either be herbicides and insecticides, which are largely sprayed during the pre-harvest stages or fungicides which can be employed at different stages depending on the crop to be used (Iqbal et al., 2009; Sharmaa et al., 2012). Insecticides are further classified into organophosphate, organochlorine, carbamates, pyrethroids and neonicotinoids. Among the classes of pesticides, organochlorine is most frequently used by the growers. Organochlorines are used to eradicate the destructive effects of sucking and chewing insects on fruits and vegetables (Hussain et al., 2002). Endosulfan is a wide-ranging organochlorine insecticide, usually used as an acaricide and insecticide around the world. It is a colorless solid and due to its role as an endocrine disruptor, acute toxicity, and potential for bioaccumulation it has become one of the most controversial insecticides. It contains a mixture of $\alpha$-and $\beta$-isomers in the ratio of 70:30. The chief degradation product of endosulfan in plants and soil is endosulfan sulfate. As endosulfan is widely used as a pesticide in agriculture, therefore its residues have been found in soil, foodstuff, surface, atmosphere, rain water and sediments (Latif et al., 2011).

Exposure of organochlorine insecticides compounds has been observed to affect the function of thyroid in preschool children. In males, decrease in sperm count, defects in birth, testicular cancer is increased due to prolonged ingestion of organochlorines. These are human disease agents and act as an environmental pollutant. It has been reported that their extended use results in reproductive abnormalities, immune suppression and cancer (Osman et al., 2010).

In order to increase the crop output farmers all over the world apply a large quantity of organochlorine pesticides during the entire growth period of fruits, crops (like cotton, tobacco) and 
vegetables especially brinjal and okra. Lack of awareness regarding integrated pest management practices is believed to be one of the major reasons of higher values of pesticide residues in okra and brinjal (Tariq, 2005). When these highly contaminated vegetables are ingested by consumer, can cause serious health hazards (Kumari et al., 2003). And if human exposure to contaminated food is constant then it indicates a shocking condition of liver damage and cancer initiation (Tariq et al., 2007). Besides their effective control of insect pest attack at the same time they are dangerous for human health and his surroundings (Schipper et al., 2008)

This paper reveals the residual level of OCPs residues $(\alpha$ endosulfan, $\beta$ endosulfan, endosulfan sulphate, $\mathrm{HCH}$, Gamma $\mathrm{HCH}, \mathrm{DDT}$ and DDE) in brinjal and okra samples from the peri-urban environment of big cities of Punjab including Faisalabad, Gujranwala and Multan and also compares the levels of OCPs residues with their maximum residual limits (MRLs).

\section{MATERIALS AND METHODS}

Selection of field: Thirty farmers, using pesticides as per their normal schedule, growing vegetables (brinjal and okra) in the peri-urban surroundings of districts Faisalabad, Gujranwala and Multan were randomly selected. Farmers were selected on the base of their distance from the city markets and their produce destination. Farmers were selected with vegetable fields within radius of $10 \mathrm{Km}$ from the main vegetable market of respective city. Preference was given to those farmers who were closer to city with the reason to assure that their produce are marketed to the nearest respective market.

Collection of samples: Thirty samples of each vegetable, at optimum maturity stage, were procured. They were kept in polyethylene air tight bags and transported to laboratory for immediate analysis. Those samples, which were not immediately analyzed due to any reason, were stored at $-40^{\circ} \mathrm{C}$ until their analysis to avoid any degradation of pesticide residues during ordinary storage.

Extraction of residues: Residues of OCPs were extracted from the homogenized sample using the method of Kadenezki et al. (1992) with some modifications illustrated by Khan et al. (2009). Ethyl acetate, an extracting solvent, was added to blended $1 \mathrm{~kg}$ chopped sample. According to this method $50 \mathrm{~g}$ of homogenized sample was taken in $250 \mathrm{~mL}$ Erlenmeyer flask. $20 \mathrm{~g}$ anhydrous sodium sulphate (analytical grade) was added and mixed in homogenized vegetable sample in flask to prevent the clot formation. $10 \mathrm{~mL}$ saturated sodium chloride was added in the mixture. $70 \mathrm{~mL}$ ethyl acetate (HPLC grade) was added in the sample. Glass beads were added in mixture to facilitate the extraction process. Mixture in flask was shaken at speed of $240-250 \mathrm{rpm}$ on a horizontal mechanical shaker for time period of 1 hour. The extract was filtered using Whatman (No. 4) filter paper, collected in inert plastic bottle and stored at $-40^{\circ} \mathrm{C}$ prior to further analysis.
Clean-up of filtered extract: Pesticides residues analysis requires high sensitivity as these are present in traces. Therefore, to get high sensitivity, cleanup operation was carried out so that interfering substances in the extract could be removed and precise measurement of residues could be done. For this reason, residues of pesticides were cleaned up using column chromatographic technique as reported by Kumari (2008). Column was prepared by using glass wool, anhydrous sodium sulphate, activated silica gel and charcoal. After washing of the prepared column with acetone (HPLC grade) loading of sample was done and the extract was eluted using $50 \mathrm{~mL}$ of acetone and hexane mixture $(3: 7 \mathrm{~V} / \mathrm{V})$ at the rate of $1 \mathrm{~mL} \mathrm{~min}^{-1}$. The cleaned up elute was received in round bottom flask and concentrated in rotary evaporator at $40^{\circ} \mathrm{C}$ to final volume of 1-1.5 mL. The concentrated elute was transferred to small vials of volume $1.5 \mathrm{~mL}$ and then completely dried by gentle nitrogen stream.

$\boldsymbol{G C}-\boldsymbol{E} \boldsymbol{C D}$ analysis: The cleaned extracts were analyzed on Agilent GC model 6890 equipped with capillary column using electron capture detector (ECD) as reported by Chandra et al. (2010). The separation of pesticide residues was done with HP-5 MS column. Nitrogen was used as the carrier gas at 9.6 psi pressure and total flow of gas was maintained at 60

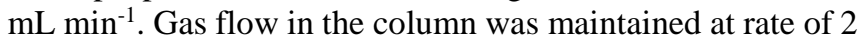

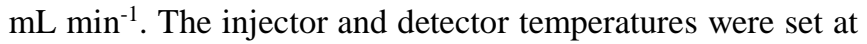
$270^{\circ} \mathrm{C}$ and $300^{\circ} \mathrm{C}$, respectively. The oven conditions were programmed as follow: initial temperature $100^{\circ} \mathrm{C}$ for $2 \mathrm{~min}$; increased up to $220^{\circ} \mathrm{C}$ at a rate of $6^{\circ} \mathrm{C} / \mathrm{min}$ held for $2 \mathrm{~min}$, increased temperature up to $260^{\circ} \mathrm{C}$ at a rate of $8^{\circ} \mathrm{C} / \mathrm{min}$ held for $2 \mathrm{~min}$ and final increased of temperature up to $300^{\circ} \mathrm{C}$ at a rate of $10^{\circ} \mathrm{C} / \mathrm{min}$ held for $10 \mathrm{~min}$. The injection volume of GC was $2 \mu \mathrm{L}$.

Curves calibration: Stock solutions of $1 \mathrm{mg} / \mathrm{ml}$ for each pesticide were prepared in methanol followed by number of dilutions ranging from 0.01 to $10 \mu \mathrm{g} / \mathrm{ml}$ in methanol. The GCECD was standardized on the same day as samples were run. A mix standards solution was also prepared in methanol to reduce error. Standards were analysed by injecting $2 \mu \mathrm{L}$ of each standard under study and mix standard. Standard curve was plotted by area under peaks versus concentrations of samples by simple linear regression. Amount of each pesticide was calculated on base of slope of standard curve.

Recovery studies: Method validation was calculated by recovery studies of all pesticide residues determined in vegetables. Recoveries were carried out by spiking blank samples with each pesticide under study at rate of $500 \mu \mathrm{g} / \mathrm{Kg}$ and $1000 \mu \mathrm{g} / \mathrm{Kg}$. Blank samples were determined by GCECD containing no pesticide residues. Recoveries were found to be $80-110 \%$ (Jansson et al., 2004).

Statistical methods: The concentration of pesticide residues in samples were expressed in form of mean and standard deviation (SD). The mean and standard deviation was calculated by using Microsoft Excel 2010. 


\section{RESULTS}

Incidence of pesticide residues in vegetables: 180 samples of vegetables were collected from farms and analyzed for OC pesticide residues i.e. $\alpha$-Endosulfan, $\beta$-Endosulfan, Endosulfan sulphate, $\mathrm{HCH}$, Gamma HCH, DDE and DDT.

Occurrence and levels of endosulfan and its metabolites: 30 samples of okra and brinjal were analyzed in triplicate for each pesticide residue i.e. $\alpha$-endosulfan, $\beta$-endosulfan, endosulfan sulphate, $\mathrm{HCH}$, gamma $\mathrm{HCH}$, DDE and DDT. Mean residue levels for detectable $\alpha$ endosulfan in okra and brinjal were as follow: Faisalabad, $0.0229 \mathrm{mg} \mathrm{kg}^{-1}$ and 0.0172 $\mathrm{mg} \mathrm{kg}{ }^{-1}$; Gujranwala, $0.1122 \mathrm{mg} \mathrm{kg}^{-1}$ and $0.1008 \mathrm{mg} \mathrm{kg}$; Multan, $0.0625 \mathrm{mg} \mathrm{kg}^{-1}$ and $0.0534 \mathrm{mg} \mathrm{kg}^{-1}$. Overall 56.6, 50 and $60 \%$ samples of okra, and 46.66, 40 and $46.66 \%$ samples of brinjal were found contaminated with $\alpha$-endosulfan (Table 1). 3 out of 17,2 out of 15 and 2 out of 18 contaminated samples of okra exceeded the recommended MRL ( $\left.0.5 \mathrm{mg} \mathrm{kg}^{-1}\right)$. Similarly, 2 out of 14,1 out of 12, and 3 out of 14 contaminated samples of brinjal exceeded the MRL $0.5 \mathrm{mg} \mathrm{kg}{ }^{-1}$ collected from Faisalabad, Gujranwala and Multan, respectively (Table 2). Mean residue levels for detectable $\beta$-endosulfan in okra and brinjal were as follow: Faisalabad, $0.1944 \mathrm{mg} \mathrm{kg}^{-1}$ and $0.098 \mathrm{mg} \mathrm{kg}^{-1}$; Gujranwala, $0.0301 \mathrm{mg} \mathrm{kg}^{-1}$ and $0.0284 \mathrm{mg} \mathrm{kg}^{-1}$; Multan, $0.1252 \mathrm{mg} \mathrm{kg}^{-1}$ and $0.1395 \mathrm{mg} \mathrm{kg}^{-1}$, respectively. Overall 50, 53.33 and
$56.66 \%$ samples of okra, and 42.33, 56.66 and $36.66 \%$ samples of brinjal showed the presence of $\beta$-endosulfan (Table 1). 2 out of 15 contaminated samples of okra and 2 out of 13 contaminated samples of brinjal showed higher values than their MRL from Faisalabad; 3 out of 16 contaminated samples of brinjal and 3 out of 17 contaminated samples of okra showed higher values than their MRL from Gujranwala; and 3 out of 17 contaminated samples of brinjal and 3 out of 11 contaminated samples of okra showed higher values than their MRL (0.05 mg kg-1) from Multan (Table 2). Samples analyzed for endosulfan sulphate residues had showed the scenario of detectable residues as: mean residue levels for detectable endosulfan sulphate in okra and brinjal in the samples from Faisalabad, $0.055 \mathrm{mg} \mathrm{kg}^{-1}$ and $0.0549 \mathrm{mg} \mathrm{kg}^{-1}$; Gujranwala, $0.1288 \mathrm{mg} \mathrm{kg}^{-1}$ and $0.0459 \mathrm{mg} \mathrm{kg}^{-1}$; Multan, $0.01478 \mathrm{mg} \mathrm{kg}^{-1}$ and $0.0208 \mathrm{mg} \mathrm{kg}^{-1}$, respectively. On an average $63.33,46.66$ and $53.33 \%$ samples of okra, and 50, 50 and $46.66 \%$ samples of brinjal had the residues of endosulfan sulphate (Table 1). 2/19, 3/14, 3/16 contaminated samples of okra and $3 / 15,2 / 15,2 / 14$ of contaminated samples of brinjal were exceeded the recommended MRL (0.01 $\left.\mathrm{mg} \mathrm{kg} \mathrm{kg}^{-1}\right)$ (Table 2).

Occurrence and levels of $\mathrm{HCH}$ and its metabolite: Maximun residue levels for detectable $\mathrm{HCH}$ in okra $\left(0.0184 \mathrm{mg} \mathrm{kg}^{-1}\right)$ and brinjal $\left(0.0143 \mathrm{mg} \mathrm{kg}^{-1}\right)$ were found in Faisalabad (Table 1). The contamination rate in okra was 30, 23.33 and

Table 1. Mean and contamination rate for detectable samples in okra and brinjal.

\begin{tabular}{|c|c|c|c|c|c|c|}
\hline \multirow[t]{3}{*}{ Pesticides } & \multirow[t]{3}{*}{ Area } & \multicolumn{4}{|c|}{ Vegetable } & \multirow{3}{*}{$\begin{array}{c}\text { MRLs } \\
\left(\mathrm{mg} \mathrm{Kg}^{-1}\right)\end{array}$} \\
\hline & & \multicolumn{2}{|l|}{ Okra } & \multicolumn{2}{|l|}{ Brinjal } & \\
\hline & & Mean + S.D. $\left(\mathrm{mg} \mathrm{Kg}^{-1}\right)$ & C.R (\%) & Mean + S.D. $\left(\mathrm{mg} \mathrm{Kg}^{-1}\right)$ & C.R (\%) & \\
\hline \multirow[t]{3}{*}{$\alpha$-Endosulfan } & Faisalabad & $0.0229 \pm 0.0339$ & 56.66 & $0.0172 \pm 0.0339$ & 46.66 & 0.05 \\
\hline & Gujranwala & $0.1122 \pm 0.0396$ & 50.00 & $0.1008 \pm 0.0396$ & 40.00 & \\
\hline & Multan & $0.0625 \pm 0.0396$ & 60.00 & $0.0534 \pm 0.0396$ & 46.66 & \\
\hline \multirow[t]{3}{*}{$\beta$-Endosulfan } & Faisalabad & $0.1944 \pm 0.0339$ & 50.00 & $0.0980 \pm 0.0339$ & 42.33 & 0.05 \\
\hline & Gujranwala & $0.0301 \pm 0.0396$ & 53.33 & $0.0284 \pm 0.0396$ & 56.66 & \\
\hline & Multan & $0.1252 \pm 0.0396$ & 56.66 & $0.1395 \pm 0.0396$ & 36.66 & \\
\hline Endosulfan & Faisalabad & $0.0550 \pm 0.0339$ & 63.33 & $0.0549 \pm 0.0339$ & 50.00 & 0.05 \\
\hline \multirow[t]{2}{*}{ Sulphate } & Gujranwala & $0.1288 \pm 0.0396$ & 46.66 & $0.0459 \pm 0.0396$ & 50.00 & \\
\hline & Multan & $0.0148 \pm 0.0396$ & 53.33 & $0.0208 \pm 0.0396$ & 46.66 & \\
\hline \multirow[t]{3}{*}{$\mathrm{HCH}$} & Faisalabad & $0.0184 \pm 0.0339$ & 30.00 & $0.0143 \pm 0.0339$ & 36.66 & 0.01 \\
\hline & Gujranwala & $0.0065 \pm 0.0396$ & 23.33 & $0.0065 \pm 0.0396$ & 33.33 & \\
\hline & Multan & $0.0061 \pm 0.0396$ & 36.66 & $0.0059 \pm 0.0396$ & 33.33 & \\
\hline \multirow[t]{3}{*}{$\gamma-\mathrm{HCH}$} & Faisalabad & $0.0415 \pm 0.0339$ & 33.33 & $0.0129 \pm 0.0339$ & 26.66 & 0.01 \\
\hline & Gujranwala & $0.0573 \pm 0.0396$ & 36.66 & $0.0410 \pm 0.0396$ & 43.33 & \\
\hline & Multan & $0.0600 \pm 0.0396$ & 40.00 & $0.0438 \pm 0.0396$ & 43.33 & \\
\hline \multirow[t]{3}{*}{ DDT } & Faisalabad & $0.0107 \pm 0.0339$ & 40.00 & $0.0156 \pm 0.0339$ & 46.66 & 0.05 \\
\hline & Gujranwala & $0.0080 \pm 0.0396$ & 40.00 & $0.0071 \pm 0.0396$ & 50.00 & \\
\hline & Multan & $0.0104 \pm 0.0396$ & 33.33 & $0.0097 \pm 0.0396$ & 36.33 & \\
\hline \multirow[t]{3}{*}{ DDE } & Faisalabad & $0.0052 \pm 0.0339$ & 36.66 & $0.0097 \pm 0.0339$ & 43.33 & 0.05 \\
\hline & Gujranwala & $0.0158 \pm 0.0396$ & 46.66 & $0.0169 \pm 0.0396$ & 30.00 & \\
\hline & Multan & $0.0149 \pm 0.0396$ & 53.33 & $0.0063 \pm 0.0396$ & 40.00 & \\
\hline
\end{tabular}

C.R = Contamination Rate; MRLs = Maximum Residual Limits; Maximum residual limits (MRL) refer to EC directives (2005). 
Table:2 Organochlorine pesticides residues in okra and brinjal with \% MRL

\begin{tabular}{|c|c|c|c|c|c|c|c|c|c|c|c|}
\hline \multirow[t]{3}{*}{ Pesticides } & \multirow[t]{3}{*}{ Area } & \multicolumn{10}{|c|}{ Vegetable } \\
\hline & & \multicolumn{5}{|c|}{ Okra } & \multicolumn{5}{|c|}{ Brinjal } \\
\hline & & $\mathbf{n}$ & Cont. & N.D & $>$ MRL & $>$ MRL (\%) & $\mathbf{n}$ & Cont. & N.D & $>$ MRL & $>$ MRL (\%) \\
\hline \multirow[t]{3}{*}{$\alpha$-Endosulfan } & Faisalabad & 30 & 17 & 13 & 3 & 10 & 30 & 14 & 16 & 2 & 6 \\
\hline & Gujranwala & 30 & 15 & 15 & 2 & 6 & 30 & 12 & 18 & 1 & 3.33 \\
\hline & Multan & 30 & 18 & 12 & 2 & 6 & 30 & 14 & 16 & 3 & 10 \\
\hline \multirow[t]{3}{*}{$\beta$-Endosulfan } & Faisalabad & 30 & 15 & 15 & 2 & 6 & 30 & 13 & 17 & 2 & 6 \\
\hline & Gujranwala & 30 & 16 & 14 & 3 & 10 & 30 & 17 & 13 & 3 & 10 \\
\hline & Multan & 30 & 17 & 13 & 3 & 10 & 30 & 11 & 19 & 2 & 6 \\
\hline Endosulfan & Faisalabad & 30 & 19 & 11 & 2 & 6 & 30 & 15 & 15 & 3 & 10 \\
\hline \multirow{2}{*}{ sulphate } & Gujranwala & 30 & 14 & 16 & 3 & 10 & 30 & 15 & 15 & 2 & 6 \\
\hline & Multan & 30 & 16 & 14 & 3 & 10 & 30 & 14 & 16 & 2 & 6 \\
\hline \multirow[t]{4}{*}{$\mathrm{HCH}$} & Faisalabad & 30 & 9 & 21 & 0 & 0 & 30 & 10 & 20 & 0 & 0 \\
\hline & Gujranwala & 30 & 7 & 23 & 0 & 0 & 30 & 10 & 20 & 0 & 0 \\
\hline & Multan & 30 & 11 & 19 & 0 & 0 & 30 & 10 & 20 & 0 & 0 \\
\hline & Faisalabad & 30 & 10 & 20 & 0 & 0 & 30 & 8 & 22 & 0 & 0 \\
\hline \multirow[t]{2}{*}{$\gamma-\mathbf{H C H}$} & Gujranwala & 30 & 11 & 19 & 0 & 0 & 30 & 13 & 17 & 0 & 0 \\
\hline & Multan & 30 & 12 & 18 & 0 & 0 & 30 & 13 & 17 & 0 & 0 \\
\hline \multirow[t]{3}{*}{ DDT } & Faisalabad & 30 & 12 & 18 & 0 & 0 & 30 & 14 & 16 & 0 & 0 \\
\hline & Gujranwala & 30 & 12 & 18 & 0 & 0 & 30 & 15 & 15 & 0 & 0 \\
\hline & Multan & 30 & 10 & 20 & 0 & 0 & 30 & 11 & 19 & 0 & 0 \\
\hline \multirow[t]{3}{*}{ DDE } & Faisalabad & 30 & 11 & 21 & 0 & 0 & 30 & 13 & 17 & 0 & 0 \\
\hline & Gujranwala & 30 & 14 & 16 & 0 & 0 & 30 & 9 & 21 & 0 & 0 \\
\hline & Multan & 30 & 14 & 16 & 0 & 0 & 30 & 12 & 18 & 0 & 0 \\
\hline
\end{tabular}

$\mathrm{n}=$ Total Sample; N.D= Not Detected $;$ Cont.$=$ Contaminated $; \mathrm{MRL}=$ Maximum Residual Limit

$36.66 \%$ and in brinjal was $36.66,33.33$ and $33.33 \%$ (Table 1 ) and no sample of okra and brinjal were exceeded the recommended MRL $\left(0.5 \mathrm{mg} \mathrm{kg}^{-1}\right)$ (Table 2). Analysis of okra and brinjal samples for gamma $\mathrm{HCH}$ showed that 10,11, 12 samples of okra and 8,13,13 samples of brinjal were contaminated from Faisalabad, Gujranwala and Multan, respectively but no sample exceeded its MRL. Maximum mean residue levels for detectable gamma $\mathrm{HCH}$ for okra $0.0573 \mathrm{mg} \mathrm{kg}^{-1}$ and brinjal $0.0410 \mathrm{mg} \mathrm{kg}^{-1}$ were found in Gujranwala (Table 1) but no sample exceeded its MRL (0.05 $\mathrm{mg} \mathrm{kg}^{-1}$ ) (Table 2).

Occurrence and levels of DDT and its metabolite: Samples analyzed for DDT residues had showed the scenario of detectable residues as: mean residue levels for detectable DDT in okra and brinjal in the samples from Faisalabad, $0.0107 \mathrm{mg} \mathrm{kg}^{-1}$ and $0.0156 \mathrm{mg} \mathrm{kg}^{-1}$; Gujranwala, $0.008 \mathrm{mg}$ $\mathrm{kg}^{-1}$ and $0.0071 \mathrm{mg} \mathrm{kg}^{-1}$; Multan, $0.0104 \mathrm{mg} \mathrm{kg}^{-1}$ and 0.0097 $\mathrm{mg} \mathrm{kg}^{-1}$ respectively. On an average 40, 40 and $33.33 \%$ samples of okra, and 46.66, 50 and $36.33 \%$ samples of brinjal had the residues of DDT (Table 1). 12, 12, 10 samples of okra and $14,15,11$ samples of brinjal were contaminated with DDT collected from peri-urban areas of Faisalabad, Gujranwala and Multan, respectively. No samples of okra and brinjal exceeded the recommended MRL (0.01 mg kg-1) (Table 2). Mean residue levels for detectable DDE in okra and brinjal were as follow: Faisalabad, $0.0052 \mathrm{mg} \mathrm{kg}^{-1}$ and 0.0097 $\mathrm{mg} \mathrm{kg}{ }^{-1}$; Gujranwala, $0.0158 \mathrm{mg} \mathrm{kg}^{-1}$ and $0.0169 \mathrm{mg} \mathrm{kg}^{-1}$;
Multan, $0.0149 \mathrm{mg} \mathrm{kg}^{-1}$ and $0.0063 \mathrm{mg} \mathrm{kg}^{-1}$. Overall 36.66, 46.66 and $53.33 \%$ samples of okra, and $43.33,30$ and $40 \%$ samples of brinjal were found contaminated with DDE (Table 1). 11, 14, 14 samples of okra and 13, 9, 12 samples of brinjal had residues of DDE procured from peri-urban areas of Faisalabad, Gujranwala and Multan, respectively. No samples of okra exceeded the recommended MRL $(0.5 \mathrm{mg}$ $\mathrm{kg}^{-1}$ ) similarly no samples of brinjal exceeded the MRL 0.5 $\mathrm{mg} \mathrm{kg}^{-1}$ (Table 2).

\section{DISCUSSION}

In this study 7 pesticides $\alpha$-Endosulfan, $\beta$-Endosulfan, Endosulfan sulphate, $\mathrm{HCH}$, Gamma HCH, DDE and DDT in okra and brinjal were analyzed. Samples were taken from peri-urban areas of 3 cities i.e. Faisalabad, Multan and Gujranwala about $200 \mathrm{Km}$ apart from each other belong to Punjab Pakistan. Out of 90 samples of each pesticide 50 samples were contaminated with $\alpha$-endosulfan, $48 \beta$ endosulfan, 49 endosulfan sulphate, $27 \mathrm{HCH}, 32$ gamma $\mathrm{HCH}, 34 \mathrm{DDT}$ and 39 with DDE. Out of contaminated 7 and 6 samples of $\alpha$-Endosulfan; 8 and $7 \beta$-Endosulfan; 8 and 7 endosulfan sulphate for okra and brinjal respectively were higher than MRLs established by EU (Table 2). While HCH, gamma $\mathrm{HCH}$, DDT and DDE contaminated samples were below MRLs established by EU (Table 2). 
The results of present findings are in line with the study of Adeyeye and Osibanjo (1999) who reported that 95\% vegetable samples were contaminated with low levels of $\mathrm{HCH}$ and none of the samples were exceeding the maximum residues limits established by FAO. Our results also showed the presence of $\mathrm{HCH}$ and DDT metabolites in vegetables samples and their residues are well within the safe limits of both the FAO and EU. However, in the present investigations only endosulfan residues were exceeded beyond the maximum limits. In a previous study by Randhawa et al. (2007), endosulfan residues was determined in six different vegetables grown under Faisalabad environment and some vegetables were reported to be having higher residues of endosulfan. Afterwards in the year 2011 the use of endosulfan for direct application on fruits, vegetables etc, was banned in Pakistan. The possible reasons for high endosulfan residues on studied vegetables may be the long persistence of endosulfan in the peri-urban farming system of Faisalabad, Gujranwala and Multan. The other probable reason may be the injudicious and unregulated use of endosulfan by the farmers. Although endosulfan has been banned for direct application to perishable horticultural commodities but present study shows that endosulfan is still available in the market and farmers are applying it on their crops. This is really damaging and alarming situation that needs immediate attention of the government and other related organization. In another study conducted for safety assessment of different vegetables including brinjal, Latif et al. (2011) reported that $48 \%$ samples of okra were contaminated with different pesticide residues. Moreover, the higher residues of enbdosulfan can also be decreased by washing of vegetables with portable water to safe limits (Sheikh et al., 2012 and Randhawa et al., 2014).

The mean concentration of $\mathrm{HCH}$ and $\gamma-\mathrm{HCH}$ in okra and brinjal were 0.01 and $0.008 ; 0.053$ and $0.033 \mathrm{ppm}$ respectively. Adeyeye and Osibanjo (1999) found that large number of samples were contaminated with $\mathrm{HCH}$ and no sample was exceeding the MRLs. These results are also in line with the findings of Bempah et al. (2012). They collected 240 samples of vegetables from Ghana in years 2010 and 2011 and found that $74 \%$ samples were contaminated with different organochlorine pesticides but none of the sample was exceeding the MRL for $\mathrm{HCH}$. Residues of DDT and their metabolites were found in $71.9 \%$ of vegetable samples and $31.48 \%$ samples were above the maximum residue levels. Similar results for some fruits were reported by Parveen et al. (2011). All fruit samples were contaminated with pesticides residues except banana; in a study carried out in Nawabshah Sindh (Anwar et al., 2011).

Vegetables are crops of short duration. It is necessary to spray a pesticide on crop plants repeatedly during the entire period of growth and sometimes even at the harvesting stage in subtropical climate prevailing during growth and maturity of vegetables (Kumari et al., 2003). This contamination of pesticides to crops and environment is due to their use, as of result of their toxicity to health and environment; progressed countries have banned use of these persistent chlorinated contaminants. In Pakistan large numbers of pesticides are used to control pests which resulted in contamination of soil and ground water (Tariq et al., 2007). As a result, vegetables grown in/on contaminated soils can uptake pesticides residues from soil and ground water.

Conclusion: This study provides organochlorine pesticide residues status in okra and brinjal vegetables from peri-urban farming system of some cities of Punjab. Pesticide residues were found in all the vegetable samples (okra and brinjal) from peri-urban areas of Punjab. From all these areas, Gujranwala recorded the highest pesticide residues, followed by Multan and Faisalabad. The contamination level of pesticides residues in vegetables must be considered as a major food safety and health risk to human life. Furthermore, it is suggested that a wide range of studies on monitoring of fruits and vegetables grown in different agro climate regions of Pakistan should be undertaken for contamination with pesticide residues.

\section{REFERENCES}

Adeyeye, A. and O. Osibanjo. 1999. Residues of OC pesticides in fruits, vegetables and tubers from Nigerian markets. The Sci. Total Environ. 231:227-233.

Anwar, T., I. Ahmad and S. Tahir. 2011. Determination of pesticide residues in fruits of Nawabshah District, Sindh, Pakistan. Pak. J. Bot. 43:1133-1139.

Bempah, C.K., A. Buah-Kwofie, E. Enimil, B. Blewu and G. Agyei-Martey. 2012. Residues of organochlorine pesticides in vegetables marketed in Greater Accra Region of Ghana. Food Control. 25:537-542.

Chandra, S., A.N. Mahindrakar and L.P. Shinde. 2010. Determination of cypermethrin and chlorpyrifos in vegetables by GC-ECD. Int. J. Chem. Tech. Res. 2:908911.

European Commission (EC). 2005. Commission amending Regulation (EC) No 396/2005 of the European Parliament and of the Council to establish Annex I listing the food and feed products to which maximum levels for pesticide residues apply. Official Journal of the European Union L 70, 16 March 2005, pp.1-16.

Guler, G.O., Y.S. Cakmak, Z. Dagli, A. Aktumsek and H. Ozparlak. 2010. Organo- chlorine pesticide residues in wheat from Konya region, Turkey. Food Chem. Toxicol. 48:1218-1221.

Husssain, S., T. Masud and K. Ahad. 2002. Determination of pesticide residues in selected varieties of mango. Pak. J. Nutr. 1:41-52.

Iqbal, M.F., U. Maqbool, I. Perveez, M. Farooq and M.R. Asi. 2009. Monitoring of insecticide residues in brinjal 
collected from market of Nosheravirkan. J. Anim. Plant Sci.19:90-93.

Jansson, C., T. Pihlström, B.G. Osterdahl and K.E. Markides. 2004. A new multi-residue method for analysis of pesticide residues in fruit and vegetables using liquid chromatography with tandem mass spectrometric detection. J. Chromatography A. 1023:93-104.

Kadenezki, L., Z. Arpad, I. Garth, A. Ambrus, L. Gyorfi, G. Reese and W. Ebing. 1992. Column extraction of residues of several pesticides from fruits and vegetables: A simple multi residue analysis method. The J. AOAC Int. 75:53-61.

Khan, B.A., A. Farid, M.R. Asi, H. Shah and A.K. Badshah. 2009. Determination of residues of trichlorfon and dimethoate on guava using HPLC. Food Chem. 114:286288.

Kumari, B. 2008. Effects household processing on Reduction of pesticides residues in vegetables. ARPN J. Agric. Biol. Sci. 3:46-51.

Kumari, B., R. Kumar, V.K. Madan, R. Singh, J. Singh and T.S. Kathpal. 2003. Magnitude of pesticidal contamination in winter vegetables from Hisar, Haryana. Environ. Monit. Asses. 87:311-318.

Latif, Y., S.T.H. Sherazi and M.I. Bhanger. 2011. Assessment of pesticide residues in commonly used vegetables in Hyderabad, Pakistan. Ecotox. Environ. Safety 74:22992303.

Osman, K.A., A.M. Al-Humaid, S.M. Al-Rehiayani and K.N. Al-Redhaiman. 2010. Monitoring of pesticide residues in vegetables marketed in Al-Qassim region, Saudi Arabia. Ecotox. Environ. Safety. 73:1433-1439.

Parveen, Z., Riazuddin, S. Iqbal, M.I. Khuhro, M.A. Bhutto and M. Ahmed. 2011. Monitoring of multiple pesticide residues in some fruits in Karachi, Pakistan. Pak. J. Bot. 43:1915-1918.

Randhawa, M.A., F.M. Anjum, M.R. Asi, A. Ahmed and H. Nawaz. 2014. Field incurred endosulfan residues in fresh and processed vegetables and dietary intake assessment. Int. J. Food Prop. 17:1109-1115.

Randhawa, M.A., F.M. Anjum, A. Ahmed and M.S. Randhawa. 2007. Field incurred chlorpyrifos and 3, 5, 6trichloro-2-pyridinol residues in fresh and processed vegetables. Food Chem.103:1016-1023.

Schipper, P.N., M.J. Vissers and A.M. van der Linden. 2008. Pesticides in groundwater and drinking water wells: Overview of the situation in the Netherlands. Water Sci. Technol. 57:1277-1286.

Sharmaa, A., M. Mishraa, A.K. Shuklaa, R. Kumarb, M.Z. Abdinc and D.K. Chowdhuria. 2012. Organochlorine pesticide, endosulfan induced cellular and organismal response in Drosophila melanogaster. J. Hazard. Mat. 221:275-287.

Sheikh, S.A., S.M. Nizamani, A.A. Jamali, A.A. Panhwar, M.J. Channa and B.N. Mirani. 2012. Removal of pesticide residues from okra vegetable through traditional processing. J. Basic Appl.Sci.8:79-85.

Tariq, M.I. 2005. Leaching and degradation of cotton pesticides on different soil series of cotton growing areas of Punjab, Pakistan in Lysimeters. Ph.D. Thesis. University of Punjab, Lahore, Pakistan. pp.45-52.

Tariq, M.I., S. Afzal, I. Hussain and N. Sultana. 2007. Pesticides exposure in Pakistan: A review. Environ. Int. 33:1107-1122. 